\title{
Convergence results of multi-valued nonexpansive mappings in Banach spaces
}

Huimin $\mathrm{He}^{1 *}$, Sanyang Liu' and Rudong Chen ${ }^{2}$

Dedicated to Professor Shih-sen Chang on the occasion of his 80th birthday

"Correspondence:

huiminhe@126.com

${ }^{1}$ School of Mathematics and

Statistics, Xidian University, Xi'an,

710071, China

Full list of author information is

available at the end of the article

\begin{abstract}
The purpose of this paper is to establish two new iteration schemes as follows: $x_{n}=\alpha_{n} x_{n-1}+\left(1-\alpha_{n}\right) y_{n}, y_{n} \in T x_{n}, n \geq 1, x_{n}^{\prime}=\beta_{n} u+\alpha_{n} x_{n-1}^{\prime}+\left(1-\alpha_{n}-\beta_{n}\right) y_{n}^{\prime} y_{n}^{\prime} \in T x_{n}^{\prime}$ $n \geq 1$, for a multi-valued nonexpansive mapping $T$ in a uniformly convex Banach space and prove that $\left\{x_{n}\right\}$ and $\left\{x_{n}^{\prime}\right\}$ converge strongly to a fixed point of $T$ under some suitable conditions, respectively. Moreover, a gap in Sahu (Nonlinear Anal. 37:401-407, 1999) is found and revised.
\end{abstract}

MSC: 47H04; 47H10;47J25

Keywords: multi-valued nonexpansive mappings; fixed point; strong convergence; implicit iteration

\section{Introduction}

Let $E$ be a Banach space, $K$ be a nonempty, closed, and convex subset of $E$. We denote the family of all subsets of $E$ by $2^{E}$, the family of nonempty, closed, and bounded subsets of $E$ by $C B(E)$, the family of nonempty compact subsets of $E$ by $C(E)$, and the family of nonempty, compact, and convex subsets of $E$ by $C C(E)$. Let $H(\cdot, \cdot)$ be Hausdorff metric on $C B(E)$, i.e.,

$$
H(A, B)=\max \left\{\sup _{x \in A} d(x, B), \sup _{x \in B} d(x, A)\right\} \quad \forall A, B \in C B(E),
$$

where $d(x, B)=\inf \{\|x-y\|: y \in B\}$.

A multi-valued mapping $T: K \rightarrow C B(K)$ is called nonexpansive (respectively, contractive), if for any $x, y \in K$, we have

$$
\begin{aligned}
& H(T x, T y) \leq\|x-y\| \\
& (\text { respectively, } H(T x, T y) \leq k\|x-y\| \text { for some } k \in[0,1)) .
\end{aligned}
$$

A point $x$ is called a fixed point of $T$ if $x \in T x$. In this paper, $F(T)$ stands for the fixed point set of the mapping $T$.

In 1968, Markin [1] firstly established the nonexpansive multi-valued convergence results in Hilbert space. Banach's contraction principle was extended to a multi-valued contraction by Nadler [2] in 1969.

( 2014 He et al.; licensee Springer. This is an Open Access article distributed under the terms of the Creative Commons Attribution License (http://creativecommons.org/licenses/by/2.0), which permits unrestricted use, distribution, and reproduction in any medium, provided the original work is properly cited. 
In 1974, a breakthrough was achieved by TC Lim using Edelstein's method of asymptotic centers [3].

Theorem 1.1 (Lim [4]) Let $K$ be a nonempty, bounded, closed, and convex subset of a uniformly convex Banach space $E$ and $T: K \rightarrow C(K)$ a multi-valued nonexpansive mapping. Then $T$ has a fixed point.

In 1990, Kirk and Massa [5] obtained another important result for the multi-valued nonexpansive mappings.

Theorem 1.2 (Kirk and Massa [5]) Let $K$ be a nonempty, bounded, closed, and convex subset of a Banach space $E$ and $T: K \rightarrow C C(K)$ a multi-valued nonexpansive mapping. Suppose that the asymptotic center in $K$ of each bounded sequence of $E$ is nonempty and compact. Then $T$ has a fixed point.

In 1999, Sahu [6] obtained the strong convergence theorems of the nonexpansive type and non-self multi-valued mappings for the following iteration process:

$$
x_{n}=t_{n} x_{0}+\left(1-t_{n}\right) u_{n}, \quad n \geq 0,
$$

where $u_{n} \in T x_{n}, x_{0} \in K, t_{n} \in(0,1)$, and $\lim _{n \rightarrow \infty} t_{n}=0$. Unfortunately, a gap exists in the proof of Theorem 1 in p.405 of [6]; there are the following inequalities:

$$
\begin{aligned}
\left\langle x_{n}-u_{n}, J\left(x_{n}-v\right)\right\rangle & =\left\langle x_{n}-v+v-u_{n}, J\left(x_{n}-v\right)\right\rangle \\
& \geq\left\|x_{n}-v\right\|^{2}-\left\|u_{n}-v\right\| \cdot\left\|x_{n}-v\right\| \\
& \geq\left\|x_{n}-v\right\|^{2}-\left\|x_{n}-v\right\|^{2}=0 .
\end{aligned}
$$

Clearly, if the above inequality holds, then the inequality $\left\|u_{n}-v\right\| \leq\left\|x_{n}-v\right\|$ must be assumed, for all $v \in F(T)$, but this inequality does not hold generally, based on the definition of the Hausdorff metric $H(\cdot, \cdot)$ on $C B(E)$, for all $v \in T(v)$.

Remark 1.1 To revise the gap we have found in Theorem 1 of [6], in this paper, we change the fixed point set of $T(F(T):=\{x \in K, x \in T x\})$ into $F(T):=\{x \in K, x=T x\}$. The above problem is solved easily. Indeed,

$$
\begin{aligned}
\left\langle x_{n}-u_{n}, J\left(x_{n}-v\right)\right\rangle & =\left\langle x_{n}-v+v-u_{n}, J\left(x_{n}-v\right)\right\rangle \\
& \geq\left\|x_{n}-v\right\|^{2}-\left\|u_{n}-v\right\| \cdot\left\|x_{n}-v\right\| \\
& \geq\left\|x_{n}-v\right\|^{2}-H\left(T x_{n}, T v\right)\left\|x_{n}-v\right\| \\
& \geq\left\|x_{n}-v\right\|^{2}-\left\|x_{n}-v\right\|^{2}=0 .
\end{aligned}
$$

In 2001, $\mathrm{Xu}$ [7] extended Theorem 1.2 to a multi-valued nonexpansive nonself-mapping and obtained the fixed theorems. Some recent fixed point results for multi-valued nonexpansive mappings can be found in [8-13] and the references therein. 
Motivated by Sahu [6] and the above results, we propose two new iteration processes (1.6) and (1.7) and we study them in this paper. Let $K$ be a nonempty, bounded, closed, and convex subset of $E$, and $u$ and $x_{0}$ be fixed elements of $K$. We have

$$
\begin{aligned}
& x_{n}=\alpha_{n} x_{n-1}+\left(1-\alpha_{n}\right) y_{n}, \quad y_{n} \in T x_{n}, n \geq 1, \\
& x_{n}^{\prime}=\beta_{n} u+\alpha_{n} x_{n-1}^{\prime}+\left(1-\alpha_{n}-\beta_{n}\right) y_{n}^{\prime}, \quad y_{n}^{\prime} \in T x_{n}^{\prime}, n \geq 1,
\end{aligned}
$$

where $\alpha_{n}, \beta_{n} \in(0,1)$ satisfy certain conditions, and we prove some strongly convergence theorems for the multi-valued nonexpansive mappings in Banach spaces. The results presented in this paper mainly extend and improve the corresponding results of Sahu [6] on the iteration algorithms.

\section{Preliminaries}

Let $E$ be a real uniformly convex Banach space and let $J$ denote the normalized duality mapping from $E$ to $2^{E^{*}}$ defined by

$$
J(x)=\left\{f \in E^{*},\langle x, f\rangle=\|x\| \cdot\|f\|,\|x\|=\|f\|\right\}, \quad \forall x \in E,
$$

where $E^{*}$ denotes the dual space of $E$ and $\langle\cdot, \cdot\rangle$ denotes the generalized duality pair. It is well known that if $E$ is smooth or if $E^{*}$ is strictly convex, then $J$ is single-valued.

Recall that the norm of Banach space $E$ is said to be Gâteaux differentiable (or $E$ is said to be smooth), if the limit

$$
\lim _{t \rightarrow 0} \frac{\|x+t y\|-\|x\|}{t}
$$

exists for each $x, y$ on the unit sphere $S(E)$ of $E$. Moreover, if for each $y$ in $S(E)$ the limit defined by (2.2) is uniformly attained for $x$ in $S(E)$, we say that the norm of $E$ is uniformly Gâteaux differentiable. It is also well known that if $E$ has a uniformly Gâteaux differentiable norm, then the duality mapping $J$ is norm-to-weak star uniformly continuous on each bounded subset of $E$.

A Banach space $E$ is called uniformly convex, if for each $\epsilon>0$ there is a $\delta>0$ such that for $x, y \in E$ with $\|x\|,\|y\| \leq 1$, and $\|x-y\| \geq \epsilon,\|x+y\| \leq 2(1-\delta)$ holds. The modulus of convexity of $E$ is defined by

$$
\delta_{E}(\epsilon)=\inf \left\{1-\left\|\frac{1}{2}(x+y)\right\|:\|x\|,\|y\| \leq 1,\|x-y\| \geq \epsilon\right\},
$$

for all $\epsilon \in[0,2] . E$ is said to be uniformly convex if $\delta_{E}(0)=0$, and $\delta(\epsilon)>0$ for all $0<\epsilon \leq 2$.

Throughout this paper, we write $x_{n} \rightarrow x$ (respectively, $x_{n} \stackrel{*}{\rightarrow} x$ ) to indicate that the sequence $x_{n}$ weakly (respectively, weak*) converges to $x$, and as usual $x_{n} \rightarrow x$ will symbolize strong convergence. In order to show our main results, the following definitions and lemmas are needed.

Let LIM be a continuous linear functional on $l^{\infty}$ satisfying $\|\operatorname{LIM}\|=1=\operatorname{LIM}(1)$. Then we know that LIM is a mean on $N$ if and only if

$$
\inf \left\{a_{n} ; n \in N\right\} \leq \operatorname{LIM}(a) \leq \sup \left\{a_{n} ; n \in N\right\}
$$


for every $a=\left(a_{1}, a_{2}, \ldots\right) \in l^{\infty}$. According to time and circumstances, we use $\operatorname{LIM}_{n}\left(a_{n}\right)$ instead of $\operatorname{LIM}(a)$. A mean LIM on $N$ is called a Banach limit if

$$
\operatorname{LIM}_{n}\left(a_{n}\right)=\operatorname{LIM}_{n}\left(a_{n+1}\right)
$$

for every $a=\left(a_{1}, a_{2}, \ldots\right) \in l^{\infty}$. Furthermore, we have the following results $[14,15]$.

Lemma 2.1 ([14, Lemma 1]) Let C be a nonempty, closed, and convex subset of a Banach space $E$ with uniformly Gâteaux differentiable norm. Let $\left\{x_{n}\right\}$ be a bounded sequence of $E$ and let $\mathrm{LIM}_{n}$ be a mean LIM on $N$ and $z \in C$. Then

$$
\operatorname{LIM}_{n}\left\|x_{n}-z\right\|^{2}=\min \operatorname{LIM}_{n}\left\|x_{n}-y\right\|^{2}
$$

if and only if

$$
\operatorname{LIM}_{n}\left\langle y-z, J\left(x_{n}-z\right)\right\rangle \leq 0
$$

for all $y \in C$.

Definition 2.1 A multi-valued mapping $T: K \rightarrow C B(K)$ is said to satisfy Condition $I$ if there is a nondecreasing function $f:[0, \infty) \rightarrow[0, \infty)$ with $f(0)=0, f(r)>0$ for $r \in(0, \infty)$ such that

$$
d(x, T x) \geq f(d(x, F(T))) \quad \text { for all } x \in K .
$$

An example of mappings that satisfy Condition I can be found in reference [16].

\section{Strong convergence theorems}

Theorem 3.1 Let E be a uniformly convex Banach space with a uniformly Gâteaux differentiable norm, $K$ be a nonempty closed convex subset of $E, T: K \rightarrow C(K)$ be a multi-valued nonexpansive mapping. Assume that $F(T) \neq \emptyset$ and $T(y)=\{y\}$ for each $y \in F(T)$. Let $\left\{x_{n}\right\}$ be an implicit Mann type iteration defined by (1.6), where $\alpha_{n} \in(0,1)$ and $\lim _{n \rightarrow \infty} \alpha_{n}=0$, then the sequence $\left\{x_{n}\right\}$ converges strongly to a fixed point of $T$.

Proof Firstly, let $\forall p \in F(T), \forall n \geq 1$, we show that $\lim _{n \rightarrow \infty}\left\|x_{n}-p\right\|$ exists and $\left\{x_{n}\right\}$ is bounded. Using (2.1), we obtain

$$
\begin{aligned}
\left\|x_{n}-p\right\|^{2} & =\left\langle\alpha_{n} x_{n-1}+\left(1-\alpha_{n}\right) y_{n}-p, j\left(x_{n}-p\right)\right\rangle \\
& =\left(1-\alpha_{n}\right)\left(y_{n}-p, j\left(x_{n}-p\right)\right\rangle+\alpha_{n}\left\langle x_{n-1}-p, j\left(x_{n}-p\right)\right\rangle \\
& \leq\left(1-\alpha_{n}\right)\left\|y_{n}-p\right\| \cdot\left\|x_{n}-p\right\|+\alpha_{n}\left\|x_{n-1}-p\right\| \cdot\left\|x_{n}-p\right\| \\
& \leq\left(1-\alpha_{n}\right) H\left(T x_{n}, T p\right) \cdot\left\|x_{n}-p\right\|+\alpha_{n}\left\|x_{n-1}-p\right\| \cdot\left\|x_{n}-p\right\| \\
& \leq\left(1-\alpha_{n}\right)\left\|x_{n}-p\right\|^{2}+\alpha_{n}\left\|x_{n-1}-p\right\| \cdot\left\|x_{n}-p\right\|,
\end{aligned}
$$

so

$$
\left\|x_{n}-p\right\|^{2} \leq\left\|x_{n-1}-p\right\| \cdot\left\|x_{n}-p\right\| .
$$


If $\left\|x_{n}-p\right\|=0$, then $\lim _{n \rightarrow \infty}\left\|x_{n}-p\right\|=0$ apparently holds.

If $\left\|x_{n}-p\right\|>0$, from (3.1) we have

$$
\left\|x_{n}-p\right\| \leq\left\|x_{n-1}-p\right\|,
$$

we find that $\left\{\left\|x_{n}-p\right\|\right\}$ is a decreasing sequence, so

$$
\lim _{n \rightarrow \infty}\left\|x_{n}-p\right\|
$$

exists. Hence $\left\{x_{n}\right\}$ is bounded, and so is $\left\{y_{n}\right\}$.

Secondly, we show that $\lim _{n \rightarrow \infty}\left\|x_{n}-y_{n}\right\|=0$.

It follows from (1.6) and from $\left\{x_{n}\right\}$ and $y_{n} \in T x_{n}$ being bounded, that there exists a real number $M_{1}>0$ such that

$$
\begin{aligned}
& \left\|x_{n-1}-y_{n}\right\| \leq M_{1}, \\
& \left\|x_{n}-y_{n}\right\|=\alpha_{n}\left\|x_{n-1}-y_{n}\right\| \leq \alpha_{n} M_{1} .
\end{aligned}
$$

Since $\lim _{n \rightarrow \infty} \alpha_{n}=0$, we have

$$
\left\|x_{n}-y_{n}\right\| \rightarrow 0, \quad \text { as } n \rightarrow \infty
$$

therefore

$$
\lim _{n \rightarrow \infty}\left\|x_{n}-y_{n}\right\|=0
$$

We define $\phi: K \rightarrow[0, \infty)$ by $\phi(x):=\operatorname{LIM}_{n}\left\|x_{n}-x\right\|^{2}$ for each $x \in K$, since $E$ is uniformly convex (hence reflexive) and $\phi$ is continuous, convex, and $\phi(x) \rightarrow \infty$ as $\|x\| \rightarrow \infty, \phi$ attains its infimum over $K$ (see [17]). Let

$$
M:=\left\{z \in K: \phi(z)=\min _{x \in K} \phi(x)\right\} .
$$

Then $M$ is nonempty, bounded, closed, and convex (see [15, Theorem 1.3.11]).

Next, we show that $M$ is singleton.

Since $M$ and $\left\{x_{n}\right\}$ are bounded, there exists $R>0$ such that $M,\left\{x_{n}\right\} \subset B_{R}(0)$ for all $n \geq 0$. Then, by inequality (3.12) of [18] for $y_{1}, y_{2} \in M$ we have

$$
\left\|x_{n}-\frac{1}{2}\left(y_{1}+y_{2}\right)\right\|^{2} \leq \frac{1}{2}\left\|x_{n}-y_{1}\right\|^{2}+\frac{1}{2}\left\|x_{n}-y_{2}\right\|^{2}-\frac{1}{4} g\left(\left\|y_{1}-y_{2}\right\|\right) .
$$

If $y_{1} \neq y_{2}$, we have

$$
r:=\phi\left(\frac{1}{2}\left(y_{1}+y_{2}\right)\right) \leq \frac{1}{2} \phi\left(y_{1}\right)+\frac{1}{2} \phi\left(y_{2}\right)-\frac{1}{4} g\left(\left\|y_{1}-y_{2}\right\|\right)<r .
$$

This is a contradiction. Therefore, $M$ has a unique element. 
Now we show that $z \in M$ is the fixed point of $T$. Since $T$ is compact valued, we have some $w_{n} \in T z$ for $z \in M$ such that

$$
\left\|y_{n}-w_{n}\right\|=d\left(y_{n}, T z\right) \leq H\left(T x_{n}, T z\right) \leq\left\|x_{n}-z\right\|
$$

indeed, $w_{n}=P_{T z}\left(y_{n}\right)$, since $T z$ is a compact set, and we take $\lim _{n \rightarrow \infty} w_{n}=w \in T z$.

It follows from the above inequality that

$$
\begin{aligned}
\operatorname{LIM}_{n}\left\|x_{n}-w\right\| & \leq \operatorname{LIM}_{n}\left\|x_{n}-y_{n}\right\|+\operatorname{LIM}_{n}\left\|y_{n}-w_{n}\right\|+\operatorname{LIM}_{n}\left\|w_{n}-w\right\| \\
& =\operatorname{LIM}_{n}\left\|y_{n}-w_{n}\right\| \leq \operatorname{LIM}_{n}\left\|x_{n}-z\right\|,
\end{aligned}
$$

and hence $w \in M$, it follows that $M$ is singleton, so $w=z \in T z$.

Therefore, $z \in F(T)$ and so $T z=\{z\}$ by the assumption, and $F(T)$ is nonempty.

On the other hand, for $v \in F(T)$, we have

$$
\begin{aligned}
\left\langle x_{n}-y_{n}, J\left(x_{n}-v\right)\right\rangle & =\left\langle x_{n}-v+v-y_{n}, J\left(x_{n}-v\right)\right\rangle \\
& =\left\|x_{n}-v\right\|^{2}-\left\langle y_{n}-v, J\left(x_{n}-v\right)\right\rangle \\
& \geq\left\|x_{n}-v\right\|^{2}-\left\|y_{n}-v\right\| \cdot\left\|x_{n}-v\right\| \\
& \geq\left\|x_{n}-v\right\|^{2}-H\left(T x_{n}, T v\right) \cdot\left\|x_{n}-v\right\| \\
& \geq\left\|x_{n}-v\right\|^{2}-\left\|x_{n}-v\right\| \cdot\left\|x_{n}-v\right\|=0 .
\end{aligned}
$$

It follows from (1.6) that

$$
0 \leq\left\langle x_{n}-y_{n}, J\left(x_{n}-v\right)\right\rangle=\alpha_{n}\left\langle x_{n-1}-y_{n}, J\left(x_{n}-v\right)\right\rangle
$$

and

$$
\begin{aligned}
\left\langle x_{n}-x_{n-1}, J\left(x_{n}-v\right)\right\rangle & =\left\langle x_{n}-y_{n}, J\left(x_{n}-v\right)\right\rangle+\left\langle y_{n}-x_{n-1}, J\left(x_{n}-v\right)\right\rangle \\
& \leq\left\|x_{n}-y_{n}\right\| \cdot\left\|x_{n}-v\right\|+\left\langle y_{n}-x_{n-1}, J\left(x_{n}-v\right)\right\rangle .
\end{aligned}
$$

Hence, from (3.2), (3.3), and (3.4), we obtain

$$
\operatorname{LIM}_{n}\left\langle x_{n}-x_{n-1}, J\left(x_{n}-v\right)\right\rangle=0, \quad \forall v \in F(T)
$$

Finally, we show that $\operatorname{LIM}_{n}\left\langle x_{n-1}-v, J\left(x_{n}-v\right)\right\rangle \leq 0$. Let $s \in(0,1)$, then by Lemma 1 of [19] we get

$$
\begin{aligned}
&\left\|x_{n}-z-s\left(x_{n-1}-z\right)\right\|^{2} \\
& \leq\left\|x_{n}-z\right\|^{2}+2\left\langle-s\left(x_{n-1}-z\right), j\left(x_{n}-z-s\left(x_{n-1}-z\right)\right)\right\rangle \\
&=\left\|x_{n}-z\right\|^{2}-2 s\left\langle x_{n-1}-z, j\left(x_{n}-z\right)\right\rangle \\
& \quad-2 s\left(x_{n-1}-z, j\left(x_{n}-z-s\left(x_{n-1}-z\right)\right)-j\left(x_{n}-z\right)\right\rangle .
\end{aligned}
$$


Let $\varepsilon>0$ be arbitrary, then since $J$ is norm-to-weak* uniformly continuous on bounded subsets of $E$, there exists $\delta>0$ such that for all $s \in(0, \delta)$, we have

$$
\begin{aligned}
& \operatorname{LIM}_{n}\left\langle x_{n-1}-z, j\left(x_{n}-z\right)\right\rangle \\
& \quad \leq \frac{1}{2 s}\left[\operatorname{LIM}_{n}\left\|x_{n}-z\right\|^{2}-\operatorname{LIM}_{n}\left\|x_{n}-z-s\left(x_{n-1}-z\right)\right\|^{2}\right]+\varepsilon<\varepsilon
\end{aligned}
$$

since $z \in M$, and it is a minimizer of $\phi$ over $K$. Now, since $\varepsilon$ is arbitrary this implies that

$$
\operatorname{LIM}_{n}\left\langle x_{n-1}-z, j\left(x_{n}-z\right)\right\rangle \leq 0
$$

Combining inequalities (3.5) and (3.6) we get

$$
\operatorname{LIM}_{n}\left\langle x_{n}-z, j\left(x_{n}-z\right)\right\rangle=\operatorname{LIM}_{n}\left\|x_{n}-z\right\|^{2} \leq 0 .
$$

Therefore, there is a subsequence $\left\{x_{n_{j}}\right\}$ of $\left\{x_{n}\right\}$ which converges strongly to $z$.

Since $\lim _{n \rightarrow \infty}\left\|x_{n}-p\right\|$ exists $\forall p \in F(T)$, we get

$$
\lim _{n \rightarrow \infty}\left\|x_{n}-z\right\|=0
$$

The proof is completed.

Theorem 3.2 Let E be a uniformly convex Banach space with a uniformly Gâteaux differentiable norm, $K$ a nonempty, closed, and convex subset of $E, T: K \rightarrow C B(K)$ be a multivalued nonexpansive mapping that satisfies Condition $I$, assume $F(T) \neq \emptyset$ and $T(y)=\{y\}$ for each $y \in F(T)$. Let $\left\{x_{n}\right\}$ be an implicit Mann type iteration defined by (1.6), where $\alpha_{n} \in(0,1)$ and $\lim _{n \rightarrow \infty} \alpha_{n}=0$, then the sequence $\left\{x_{n}\right\}$ converges strongly to a fixed point of $T$.

Proof It follows from the proof of Theorem 3.1 that

$$
\lim _{n \rightarrow \infty} d\left(x_{n}, T x_{n}\right)=0 .
$$

Then Condition I implies that

$$
\lim _{n \rightarrow \infty} d\left(x_{n}, F(T)\right)=0
$$

The remainder of the proof is the same as Theorem 2.4 of [20].

Theorem 3.3 Let E be a uniformly convex Banach space with a uniformly Gâteaux differentiable norm, $K$ be a nonempty, closed, and convex subset of $E, T: K \rightarrow C(K)$ be a multivalued nonexpansive mapping. Assume that $F(T) \neq \emptyset$ and $T(y)=\{y\}$ for each $y \in F(T)$. Let $\left\{x_{n}^{\prime}\right\}$ be the modified implicit Mann type iteration defined by (1.7), where $\alpha_{n}, \beta_{n} \in(0,1)$ and $\lim _{n \rightarrow \infty} \frac{\alpha_{n}}{\beta_{n}}=\lim _{n \rightarrow \infty} \beta_{n}=0$. Then the sequence $\left\{x_{n}^{\prime}\right\}$ converges strongly to a fixed point of $T$.

Proof Firstly, let $\lambda_{n}=\frac{\beta_{n}}{1-\alpha_{n}}$ and $z_{n}=\lambda_{n} u+\left(1-\lambda_{n}\right) y_{n}^{\prime}$, then

$$
x_{n}^{\prime}=\alpha_{n} x_{n-1}^{\prime}+\left(1-\alpha_{n}\right) z_{n}
$$


Let $\forall p \in F(T), \forall n \geq 1$; we show that $\left\{x_{n}^{\prime}\right\}$ is bounded. Using (2.1), we obtain

$$
\begin{aligned}
\left\|x_{n}^{\prime}-p\right\|^{2}= & \left\langle\alpha_{n} x_{n-1}^{\prime}+\left(1-\alpha_{n}\right) z_{n}-p, j\left(x_{n}^{\prime}-p\right)\right\rangle \\
= & \left(1-\alpha_{n}\right)\left\langle z_{n}-p, j\left(x_{n}^{\prime}-p\right)\right\rangle+\alpha_{n}\left\langle x_{n-1}^{\prime}-p, j\left(x_{n}^{\prime}-p\right)\right\rangle \\
\leq & \left(1-\alpha_{n}\right)\left\langle\lambda_{n}(u-p), j\left(x_{n}^{\prime}-p\right)\right\rangle+\left(1-\alpha_{n}\right)\left\langle\left(1-\lambda_{n}\right) y_{n}^{\prime}-p, j\left(x_{n}^{\prime}-p\right)\right\rangle \\
& +\alpha_{n}\left\|x_{n-1}^{\prime}-p\right\| \cdot\left\|x_{n}^{\prime}-p\right\| \\
\leq & \left(1-\alpha_{n}\right)\left(\lambda_{n}\|u-p\| \cdot\left\|x_{n}^{\prime}-p\right\|+\left(1-\lambda_{n}\right) H\left(T x_{n}^{\prime}, T p\right)\left\|x_{n}^{\prime}-p\right\|\right) \\
& +\alpha_{n}\left\|x_{n-1}^{\prime}-p\right\| \cdot\left\|x_{n}^{\prime}-p\right\| \\
\leq & \beta_{n}\|u-p\| \cdot\left\|x_{n}^{\prime}-p\right\|+\left(1-\alpha_{n}-\beta_{n}\right)\left\|x_{n}^{\prime}-p\right\|^{2} \\
& +\alpha_{n}\left\|x_{n-1}^{\prime}-p\right\| \cdot\left\|x_{n}^{\prime}-p\right\|,
\end{aligned}
$$

so

$$
\left\|x_{n}^{\prime}-p\right\|^{2} \leq \frac{\beta_{n}}{\alpha_{n}+\beta_{n}}\|u-p\| \cdot\left\|x_{n}^{\prime}-p\right\|+\frac{\alpha_{n}}{\alpha_{n}+\beta_{n}}\left\|x_{n-1}^{\prime}-p\right\| \cdot\left\|x_{n}^{\prime}-p\right\| .
$$

If $\left\|x_{n}^{\prime}-p\right\|=0$, then $\left\{x_{n}^{\prime}\right\}$ is apparently bounded.

If $\left\|x_{n}^{\prime}-p\right\|>0$, from (3.7) we have

$$
\begin{aligned}
\left\|x_{n}^{\prime}-p\right\| & \leq \frac{\beta_{n}}{\alpha_{n}+\beta_{n}}\|u-p\|+\frac{\alpha_{n}}{\alpha_{n}+\beta_{n}}\left\|x_{n-1}^{\prime}-p\right\| \\
& \leq \max \left\{\left\|x_{n-1}^{\prime}-p\right\|,\|u-p\|\right\} \\
& \vdots \\
& \leq \max \left\{\left\|x_{0}^{\prime}-p\right\|,\|u-p\|\right\} .
\end{aligned}
$$

Thus, $\left\{x_{n}^{\prime}\right\}$ is bounded.

Secondly, we show that $\lim _{n \rightarrow \infty}\left\|x_{n}^{\prime}-y_{n}^{\prime}\right\|=0$.

It follows from (1.7) and since $\left\{x_{n}^{\prime}\right\}$ and $y_{n}^{\prime} \in T x_{n}^{\prime}$ are bounded, there exists a real number $M_{2}>0$ such that

$$
\begin{aligned}
& \left\|x_{n-1}^{\prime}-z_{n}\right\| \leq M_{2}, \\
& \left\|x_{n}^{\prime}-z_{n}\right\|=\alpha_{n}\left\|x_{n-1}^{\prime}-z_{n}\right\| \leq \alpha_{n} M_{2} .
\end{aligned}
$$

Since $\lim _{n \rightarrow \infty} \alpha_{n}=0$, we have

$$
\left\|x_{n}^{\prime}-z_{n}\right\| \rightarrow 0 \quad \text { as } n \rightarrow \infty
$$

therefore

$$
\lim _{n \rightarrow \infty}\left\|x_{n}^{\prime}-z_{n}\right\|=0
$$

Since

$$
\left\|x_{n}^{\prime}-y_{n}^{\prime}\right\| \leq\left\|x_{n}^{\prime}-z_{n}\right\|+\left\|z_{n}-y_{n}^{\prime}\right\|=\left\|x_{n}^{\prime}-z_{n}\right\|+\frac{\beta_{n}}{1-\alpha_{n}}\left\|u-y_{n}^{\prime}\right\|,
$$


then

$$
\lim _{n \rightarrow \infty}\left\|x_{n}^{\prime}-y_{n}^{\prime}\right\|=0
$$

We define $\phi: K \rightarrow[0, \infty)$ by $\phi(x):=\operatorname{LIM}_{n}\left\|x_{n}^{\prime}-x\right\|^{2}$ for each $x \in K$. Since $E$ uniformly convex (hence reflexive) and $\phi$ is continuous, convex and $\phi(x) \rightarrow \infty$ as $\|x\| \rightarrow \infty, \phi$ attains its infimum over $K$ (see, e.g., [17]). Let

$$
M:=\left\{z \in K: \phi(z)=\min _{x \in K} \phi(x)\right\} .
$$

Then $M$ is nonempty, and it is also bounded, closed, and convex (see [15, Theorem 1.3.11]). In the same way as the proof of Theorem 3.1, we see that $M$ is also singleton, and it follows from (3.9) that $z$ is the fixed point of $T$.

By Lemma 2.1, we have

$$
\operatorname{LIM}_{n}\left\langle x-z, J\left(x_{n}^{\prime}-z\right)\right\rangle \leq 0,
$$

for all $x \in K$. In particular, we have

$$
\operatorname{LIM}_{n}\left\langle u-z, J\left(x_{n}^{\prime}-z\right)\right\rangle \leq 0 .
$$

It follows from the proof of (3.6) of Theorem 3.1 that (3.6) also holds here. Thus

$$
\begin{aligned}
&\left\|x_{n}^{\prime}-z\right\|^{2} \\
&=\left\langle\beta_{n}(u-z)+\alpha_{n}\left(x_{n-1}^{\prime}-z\right)+\left(1-\alpha_{n}-\beta_{n}\right)\left(y_{n}^{\prime}-z\right), J\left(x_{n}^{\prime}-z\right)\right\rangle \\
& \leq \beta_{n}\left\langle u-z, J\left(x_{n}^{\prime}-z\right)\right\rangle+\alpha_{n}\left\langle x_{n-1}^{\prime}-z, J\left(x_{n}^{\prime}-z\right)\right\rangle \\
&+\left(1-\alpha_{n}-\beta_{n}\right)\left\{H\left(T x_{n}^{\prime}, T z\right) \cdot\left\|x_{n}^{\prime}-z\right\|\right\} \\
& \leq \beta_{n}\left\langle u-z, J\left(x_{n}^{\prime}-z\right)\right\rangle+\alpha_{n}\left\langle x_{n-1}^{\prime}-z, J\left(x_{n}^{\prime}-z\right)\right\rangle \\
&+\left(1-\alpha_{n}-\beta_{n}\right)\left\|x_{n}^{\prime}-z\right\|^{2} .
\end{aligned}
$$

Hence

$$
\begin{aligned}
\left\|x_{n}^{\prime}-z\right\|^{2} & \leq \frac{\beta_{n}}{\alpha_{n}+\beta_{n}}\left\langle u-z, J\left(x_{n}^{\prime}-z\right)\right\rangle+\frac{\alpha_{n}}{\alpha_{n}+\beta_{n}}\left\langle x_{n-1}^{\prime}-z, J\left(x_{n}^{\prime}-z\right)\right\rangle \\
& \leq\left\langle u-z, J\left(x_{n}^{\prime}-z\right)\right\rangle+\frac{\alpha_{n}}{\alpha_{n}+\beta_{n}}\left(\left\langle x_{n-1}^{\prime}-z, J\left(x_{n}^{\prime}-z\right)\right\rangle-\left\langle u-z, J\left(x_{n}^{\prime}-z\right)\right\rangle\right) \\
& \leq\left\langle u-z, J\left(x_{n}^{\prime}-z\right)\right\rangle+\frac{\alpha_{n}}{\alpha_{n}+\beta_{n}} M_{0},
\end{aligned}
$$

where $M_{0}$ is a constant such that $\left|\left\langle x_{n-1}^{\prime}-u, J\left(x_{n}^{\prime}-z\right)\right\rangle\right| \leq M_{0}$. Thus

$$
\operatorname{LIM}_{n}\left\|x_{n}^{\prime}-z\right\|^{2} \leq \operatorname{LIM}_{n}\left\langle u-z, J\left(x_{n}^{\prime}-z\right)\right\rangle+\operatorname{LIM}_{n} \frac{\frac{\alpha_{n}}{\beta_{n}}}{\frac{\alpha_{n}}{\beta_{n}}+1} M_{0}
$$


Therefore, there is a subsequence $\left\{x_{n_{j}}^{\prime}\right\}$ of $\left\{x_{n}^{\prime}\right\}$ which converges strongly to $z$. To complete the proof, suppose there is another subsequence $\left\{x_{n_{k}}^{\prime}\right\}$ of $\left\{x_{n}^{\prime}\right\}$ which converges strongly to $\bar{z}$. Then $\bar{z}$ is a fixed point of $T$ by (3.9) and $\bar{z} \in K$ because $K$ is closed. It then follows from (3.10) that

$$
\langle\bar{z}-z, J(\bar{z}-z)\rangle=\|\bar{z}-z\|^{2} \leq 0 .
$$

This proves the strong convergence of $\left\{x_{n}^{\prime}\right\}$ to $z \in F(T)$.

The proof is completed.

\section{Numerical examples}

Now, we give two real numerical examples in which the conditions satisfy the ones of Theorem 3.1 and Theorem 3.3.

Example 4.1 Let $E=\mathbb{R}, K=[-1,1], T(x)=\frac{1}{5} x, \forall x \in E$, which is nonexpansive, $\alpha_{n}=\frac{1}{n}$ for every $n \in \mathbb{N}$. Then $\left\{x_{n}\right\}$ is the sequence generated by

$$
x_{n}=\frac{1}{n} x_{n-1}+\left(1-\frac{1}{n}\right) \frac{1}{5} x_{n},
$$

and $x_{n} \rightarrow 0$ as $n \rightarrow \infty$, where 0 is the fixed point of $T$.

Example 4.2 Let $E=\mathbb{R}, K=[-1,1], T(x)=\frac{1}{2} x, \forall x \in E$, which is nonexpansive, $\alpha_{n}=\frac{1}{n^{100}}$, $\beta_{n}=\frac{1}{n^{50}}$ for every $n \in \mathbb{N}$. Then $\left\{x_{n}\right\}$ is the sequence generated by

$$
x_{n}=\frac{1}{n^{50}}+\frac{1}{n^{100}} x_{n-1}+\left(1-\frac{1}{n^{100}}-\frac{1}{n^{50}}\right) \frac{1}{2} x_{n},
$$

and $x_{n} \rightarrow 0$ as $n \rightarrow \infty$, where 0 is the fixed point of $T$.

Remark 4.1 We can prove Example 4.1 and Example 4.2 by Theorem 3.1 and Theorem 3.3, respectively, and we show two numerical experiments (Figure 1 and Figure 2) which can explain that the sequence $\left\{x_{n}\right\}$ strongly converges to 0 .

Remark 4.2 From the above numerical examples, we can see that the convergence results in this paper are important. The main reason is that the convergence of the two iteration

Figure $1 x(1)=1$, iteration steps $n=100$.

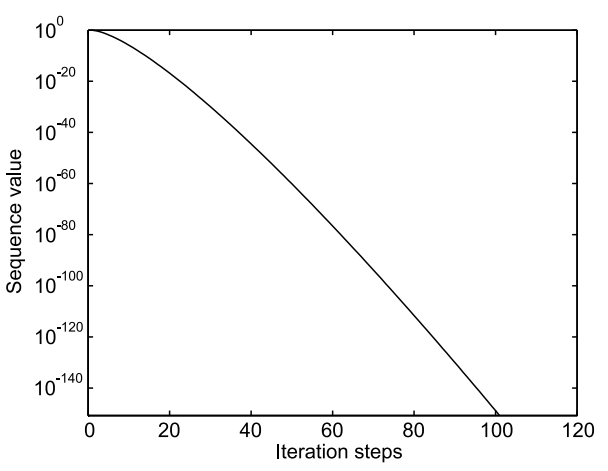


Figure $2 x(1)=0.2$, iteration steps $n=1,000$.

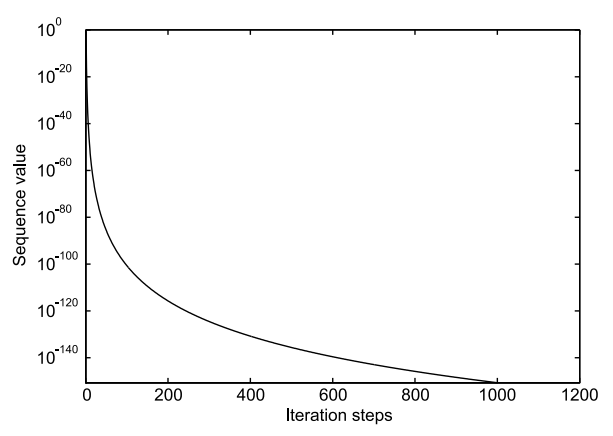

schemes in this paper can easily be implemented by the software of Matlab 7.0, so they can be applied for numerical calculations in practical problems.

\section{Competing interests}

The authors declare that they have no competing interests.

\section{Authors' contributions}

The authors read and approved the final manuscript.

\section{Author details}

${ }^{1}$ School of Mathematics and Statistics, Xidian University, Xi'an, 710071, China. ${ }^{2}$ Department of Mathematics, Tianjin Polytechnic University, Tianjin, 300160, China.

\section{Acknowledgements}

This work is supported by the Fundamental Research Funds for the Central Universities (No. K5051370004), the Natural Science Basic Research Plan in Shaanxi Province of China (No. 2014JQ1020), the National Science Foundation of China (No. 61202178 and No. 61373174), the National Natural Science Foundation of China, Tian Yuan Special Foundation (No. 11426167)

\section{Received: 30 April 2014 Accepted: 19 November 2014 Published: 04 Dec 2014}

\section{References}

1. Markin, JT: A fixed point theorem for set valued mappings. Bull. Am. Math. Soc. 74, 639-640 (1968)

2. Nadler, SB: Multi-valued contraction mappings. Pac. J. Math. 30, 475-488 (1969)

3. Edelstein, M: The construction of an asymptotic center with a fixed point property. Bull. Am. Math. Soc. 78, 206-208 (1972)

4. Lim, TC: A fixed point theorem for multi-valued nonexpansive mappings in a uniformly convex Banach space. Bull. Am. Math. Soc. 80, 1123-1126 (1974)

5. Kirk, WA, Massa, S: Remarks on asymptotic and Chebyshev centers. Houst. J. Math. 16, 357-364 (1990)

6. Sahu, DR: Strong convergence theorems for nonexpansive type and non-self multi-valued mappings. Nonlinear Anal. 37, 401-407 (1999)

7. Xu, HK: Multi-valued nonexpansive mappings in Banach spaces. Nonlinear Anal. 43, 693-706 (2001)

8. Reich, S: A fixed point theorem for locally contractive multi-valued functions. Rev. Roum. Math. Pures Appl. 17 569-572 (1972)

9. Feng, Y, Liu, S: Fixed point theorems for multi-valued contractive mappings and multi-valued Caristi type mappings. J. Math. Anal. Appl. 317, 103-112 (2006)

10. Benavides, TD, Gavira, B: The fixed point property for multi-valued nonexpansive mappings. J. Math. Anal. Appl. 328, 1471-1483 (2007)

11. Shahzad, N, Zegeye, H: On Mann and Ishikawa iteration schemes for multi-valued maps in Banach spaces. Nonlinear Anal. 71, 838-844 (2009)

12. Jung, JS: Strong convergence theorems for multi-valued nonexpansive nonself-mappings in Banach spaces. Nonlinear Anal. 66, 2345-2354 (2007)

13. Alimohammady, $\mathrm{M}$, et al.: Iterative algorithms for a new class of extended general nonconvex set-valued variational inequalities. Nonlinear Anal. 73, 3907-3923 (2010)

14. Takahashi, W, Ueda, Y: On Reich's strong convergence for resolvents of accretive operators. J. Math. Anal. Appl. 104, 546-553 (1984)

15. Takahashi, W: Nonlinear Functional Analysis. Fixed Point Theory and Its Applications. Yokohama Publishers, Yokohama (2000) (in Japanese)

16. Panyanak, B: Mann and Ishikawa iterative processes for multi-valued mappings in Banach spaces. Comput. Math. Appl. 54, 872-877 (2007)

17. Barbu, V, Precupanu, T: Convexity and Optimization in Banach Spaces. Editura Academiei RSR, Bucharest (1978)

18. Xu, HK: Inequalities in Banach spaces with applications. Nonlinear Anal. 16, 1127-1138 (1991) 
19. Morales, $\mathrm{CH}$, Jung, JS: Convergence of paths for pseudocontractive mappings in Banach spaces. Proc. Am. Math. Soc. $128,3411-3419(2000)$

20. Song, Y: Convergence of iterative algorithms for multi-valued mappings in Banach spaces. Nonlinear Anal. 70 1547-1556 (2009)

10.1186/1029-242X-2014-483

Cite this article as: He et al.: Convergence results of multi-valued nonexpansive mappings in Banach spaces. Journal of Inequalities and Applications 2014, 2014:483

Submit your manuscript to a SpringerOpen ${ }^{\odot}$ journal and benefit from:

- Convenient online submission

- Rigorous peer review

- Immediate publication on acceptance

Open access: articles freely available online

- High visibility within the field

- Retaining the copyright to your article

Submit your next manuscript at $>$ springeropen.com 